\title{
MANDA QUEM PODE, OBEDECE QUEM TEM JUÍZO
}

\author{
Ordena quién puede, obedece a quien tiene sentido
}

\author{
Order who can, obeys who a sense
}

\author{
Ivana Gonçalves Rebhahn ${ }^{1}$
}

\begin{abstract}
Resumo
Este artigo representa um recorte na temática de pesquisa da mestranda do PPGEdu, Mestrado Profissional em Educação da Universidade Federal do Pampa, Campus Jaguarão, que tem por objetivo promover a revitalização do Conselho Escolar da Escola Municipal de Ensino Fundamental Presidente João Goulart - Arroio Grande, RS, a partir do incentivo às práticas democráticas nos processos de participação. Como discussão as relações de poder na escola, a gestão democrática na escola pública e as formas de participação coletiva, mais especificamente o conselho escolar. Os sujeitos da pesquisa são os professores da escola e os membros do conselho escolar. O estudo utiliza a metodologia da pesquisa-ação intervencionista. Para coletar dados em relação à atuação do conselho escolar e à visão dos conselheiros e dos professores sobre o assunto foi aplicado um questionário com perguntas abertas. Também foi realizada a análise documental do Projeto Político Pedagógico da escola (PPP), do Regimento Escolar, das atas e do Estatuto do Conselho Escolar. O referencial teórico vai revisitando documentos oficiais a nível nacional, municipal e também da escola em estudo. Observase a necessidade de realizar formações que considerem o fortalecimento da gestão democrática, com apoio e incentivo aos espaços de participação coletiva.
\end{abstract}

Palavras-Chave: Gestão democrática; Conselho escolar; Poder; Participação.

\section{Resumen}

Este artículo representa un corte en el tema de investigación del maestro de estudiantes de PPGEdu, Master Profesional en Educación de la Universidad Federal de Pampa, Campus Jaguarão, que tiene como objetivo promover la revitalización de la Junta Escolar de la Escuela Municipal del Presidente de la Escuela Primaria João Goulart - Arroio Grande, RS, fomentando prácticas democráticas en los procesos de participación. Como discusión las relaciones de poder en la escuela, la gestión democrática en la escuela pública y las formas de participación colectiva, más específicamente el consejo escolar. Los sujetos de investigación son los maestros de escuela y los miembros de la junta escolar. El estudio utiliza la metodología de investigación de acción intervencionista. Para recopilar datos sobre el desempeño del consejo escolar y la opinión de los consejeros y maestros sobre el tema, se aplicó un cuestionario con preguntas abiertas. También se realizó el análisis documental del Proyecto Político Pedagógico de la Escuela (PPP), el Regimiento Escolar, las actas y el Estatuto del Consejo Escolar. El marco teórico revisita documentos oficiales a nivel nacional, municipal y escolar. Es necesario llevar a cabo una capacitación que considere fortalecer la gestión democrática, con apoyo y estímulo a los espacios de participación colectiva.

Palabras clave: Gestión democrática; Junta escolar; Poder; Participación

\begin{abstract}
This article represents a cut in the research theme of the student master of PPGEdu, Professional Master in Education of the Federal University of Pampa, Campus Jaguarão, which aims to promote the revitalization of the School Board of the Municipal School of Primary School President João Goulart - Arroio Grande, RS, by encouraging democratic practices in the processes of participation. As discussion the power relations in the school, the democratic management in the public school and the forms of collective participation, more
\end{abstract}

\footnotetext{
${ }^{1}$ Mestranda do PPGEdu - Universidade Federal do Pampa - Campus Jaguarão. Graduada em Matemática. Especialista em Gestão Educacional. E-mail: ivanagon@ gmail.com
} 
specifically the school council. The research subjects are the school teachers and school board members. The study uses the methodology of interventionist action research. To collect data regarding the performance of the school council and the view of counselors and teachers on the subject, a questionnaire with open questions was applied. The documentary analysis of the school's Pedagogical Political Project (PPP), the School Regiment, the minutes and the School Council Statute was also performed. The theoretical framework revisits official documents at national, municipal and school level. There is a need to conduct training that considers strengthening democratic management, with support and encouragement to spaces for collective participation.

Keywords: Democratic management; School board; Power; Participation.

\section{Introdução}

Esse artigo é um recorte na pesquisa que tem como tema principal a análise da atuação do Conselho Escolar na Escola Municipal de Ensino Fundamental Presidente João Goulart (EMEFJG). Mais especificamente procura compreender como se dá a participação e os processos decisórios na escola. Tem como caráter metodológico a pesquisa-ação intervencionista, que é a base do Programa de Pós-Graduação em Educação (PPGEdu), Curso Mestrado Profissional da Universidade Federal do Pampa, onde se desenvolveu o trabalho.

Como pesquisadora e atual diretora da EMEFJG, sou desafiada a pensar, apesar do medo e da insegurança, porém com uma vontade de buscar o novo, de encontrar na teoria as justificativas para a prática, de sair da terra firme da acomodação e ter coragem de me expor, dado a minha condição de gestora. Compactuo com a abordagem de Ribeiro, 1999:

\footnotetext{
Não há pior inimigo do conhecimento do que a terra firme. Ora, isto significa, no que nos diz respeito, que devemos deixar de lado pelo menos parte da desculpa bibliográfica. É claro que não se espera de ninguém que reinvente a roda: os autores que nos precederam deram passos formidáveis, e deles nos devemos valer para avançar. Mas é preciso que eles sejam ajudas, e não muletas (RIBEIRO, 1999, p.190).
}

A ideia não é inventar algo novo, mas pesquisar para melhorar a prática na gestão da E.M.E.F. Presidente João Goulart, busco através da teoria, as soluções para os problemas enfrentados, sempre valorizando aqueles que vieram antes e contribuíram para os avanços na educação.

O mestrado profissional tem como objetivo geral qualificar as práticas de professores no local de trabalho, na atuação em sala de aula ou na gestão. $\mathrm{O}$ meu interesse pela pesquisa surge porque estou gestora e o cargo é ocupado por indicação do executivo municipal, cargo de confiança e não uma escolha democrática através do processo de eleição. Nas escolas públicas municipais de Arroio Grande, não existe eleição para provimento do cargo de diretor. 
Pelo diagnóstico realizado, verifiquei que o conselho escolar é pouco atuante, o principal assunto das reuniões é a aplicação dos recursos financeiros, os conselheiros não têm claro as suas funções, os professores não reconhecem a atuação do conselho na escola, as reuniões não têm uma periodicidade e falta a representação do segmento alunos. Diante deste contexto, a pesquisa busca a revitalização do conselho escolar, para que a gestão seja mais participativa, colegiada e descentralizada.

Em 2002, recebi o convite para assumir a direção da E.M.E.F. Presidente João Goulart. Embora pertencente ao quadro de servidores municipais, não fazia parte do corpo docente da escola, contudo não era estranha, pois estava inserida naquele contexto por ser moradora do bairro, atuante na associação dos moradores e na comunidade local. Fiquei três anos na direção, acompanhei a fundação do Conselho Escolar, a construção do Regimento e do Projeto Político Pedagógico - PPP. Foi uma experiência profissional significativa e desafiadora. Em 2013, retornei, também por indicação, ao cargo de diretora permanecendo até 2019. Consciente da indicação ao cargo e da falta de autonomia financeira, procurei usar os princípios da gestão que estavam ao meu alcance como a participação de todos envolvidos no processo, a integração escola, família e comunidade, a transparência na aplicação dos recursos, a tomada de decisões coletivas, a ética e o comprometimento.

Como referencial teórico, a Constituição Brasileira de 1988, a Lei de Diretrizes e Bases da Educação Nacional (LDB/1996), o Plano Nacional de Educação, os cadernos do Programa Nacional de Fortalecimento dos Conselhos Escolares e o Plano Municipal de Educação do Município de Arroio Grande - RS. Trazendo também as contribuições de Vitor Henrique Paro, Genuíno Bordignon, Heloísa Lück, entre outros.

O artigo faz referência ao local da intervenção através da caracterização do contexto, situando a escola, os sujeitos envolvidos no processo e os dados do conselho escolar.

A intervenção foi através de 7 ações, 6 rodas de conversa com os membros do conselho e um encontro com toda a comunidade escolar. Na primeira roda de conversa aconteceu a composição do grupo de trabalho. Foram apresentados os dados do diagnóstico inicial e discutiu-se a proposta de trabalho com o tema de cada encontro.

A gestão precisa oportunizar espaços, mecanismos de participação coletiva para que os pais, professores, funcionários e alunos, organizados, possam contribuir na construção de uma escola mais cidadã, com ações transparentes, descentralizadas, efetivando assim a gestão democrática. 


\section{METODOLOGIA}

O estudo é de natureza qualitativa e utiliza a metodologia da pesquisa-ação. A escolha do método se deve ao fato de que não podemos pensar em gestão democrática sem a participação de todos os segmentos envolvidos. De acordo com Thiollent (2011), a pesquisaação caracteriza-se como um trabalho em que todos são chamados a participar e cooperar:

Entre as diversas definições possíveis, daremos a seguinte: a pesquisa-ação é "um tipo de pesquisa social com base empírica que é concebida e realizada em estreita associação com uma ação ou com a resolução de um problema coletivo e no qual os pesquisadores e os participantes representativos da situação ou do problema estão envolvidos de modo cooperativo ou participativo" (THIOLLENT, 2011, p. 20).

As responsabilidades devem ser compartilhadas, num trabalho em conjunto e não dividido, realizando ações articuladas nas quais, equipe diretiva, professores, supervisão, orientação, funcionários, pais e alunos, todos participem da construção de uma escola competente, somem forças, sejam comprometidos, e os alunos tenham sucesso. Conforme enfatiza Lück (2006):

A gestão democrática e compartilhada implica, portanto, a participação de todos os segmentos da escola na elaboração e execução do plano de desenvolvimento da escola, de forma articulada (LÜCK, 2006, p. 99).

Thiollent (2011), afirma que o pesquisador deve ser um sujeito do "tipo participativo", envolvido no processo de intervenção. Os membros do conselho escolar, representantes de cada segmento da escola, são os sujeitos da pesquisa.

O levantamento de dados é a primeira fase de qualquer pesquisa. Para coletar dados em relação à atuação do conselho escolar e à visão dos membros do Conselho Escolar e dos professores sobre o mesmo, foi aplicado um questionário com perguntas abertas.

Outro instrumento utilizado para coletar dados em relação à gestão democrática foi a análise dos documentos da escola, entre eles o Projeto Político Pedagógico (PPP), o Regimento Escolar, as atas e o Estatuto do Conselho Escolar.

Lüdke (1986), considera a análise documental um instrumento muito rico em informações para a coleta de dados e cita Guba e Lincoln (1981) para falar das vantagens de usar documentos:

Guba e Lincoln (1981) resumem as vantagens do uso de documentos dizendo que uma fonte tão repleta de informações sobre a natureza do contexto nunca pode ser ignorada, quaisquer que sejam os outros métodos de investigação escolhidos (LÜDKE, 1986, p.39). 
A avaliação dos resultados obtidos é apontada por Chisté (2016, p.797), como a quarta fase da pesquisa-ação, mas deverá acontecer durante toda a pesquisa. Os participantes, do grupo de pesquisa, registraram num diário as impressões de cada roda de conversa. Costa e Guindani (2012) consideram o diário de campo como um instrumento de grande valia aos procedimentos de planejamento e avaliação.

O diário de campo é um instrumento que nos possibilita retornar a uma situação já passada e nela perceber determinações que constituem o presente. Também nos permite assimilar mais facilmente a continuidade de uma intervenção que está sendo ou já foi objeto de sistematização da intervenção profissional e com a qualificação das ações (COSTA \& GUINDANI, 2012, p.270).

As rodas de conversa contaram com a presença de um pesquisador observador que participou das ações e contribuiu através de uma análise síntese de cada ação.

\subsection{Caracterização do contexto}

A Escola Municipal de Ensino Fundamental Presidente João Goulart, instituição pública educacional do Município de Arroio Grande, situada na Avenida da Saudade, número 433, no Bairro Branco Araújo.

Em 1998, a Escola Iniciou suas atividades como anexo da E.M.E.F. Silvina Gonçalves, com turmas de $6^{\mathrm{a}}, 7^{\mathrm{a}}$ e $8^{\mathrm{a}}$ série, sob o governo do Senhor Prefeito Ermínio Braga Lucena, gestão 1997-2000, tendo como diretora Nilma Cardozo.

No dia 04 de fevereiro de 1999, saiu o decreto de criação e denominação da escola, sendo determinado o dia 18 de outubro de 2000, o parecer de funcionamento e validação de estudos, portanto a data de comemoração do aniversário da escola.

O funcionamento da escola se dá nos turnos manhã e tarde, atendendo da pré-escola ao $9^{\circ}$ ano. Os alunos, na sua maioria, são de classe econômica média baixa, oriundos da zona rural e de diversos bairros do Município. A matrícula real, em 2019, é de 383 alunos distribuídos em vinte e duas turmas. O prédio tem um total de doze salas de aula, possui também uma sala de recursos improvisada temporariamente, um refeitório, uma sala de Informática, uma biblioteca em parte do corredor e quatro banheiros.

No ano de 2016 ocorreu um incêndio na escola destruindo todo o Prédio $\mathrm{n}^{\circ} 3$, sendo necessária a adequação do espaço para suprir necessidades, assim a escola está funcionando numa estrutura limitada e precária.

A escola possui cinquenta e quatro profissionais efetivos do quadro dos servidores municipais de Arroio Grande, dois profissionais contratados e quatro monitores estagiários do 
Centro de Integração Empresa - Escola (CIEE). A equipe gestora é formada pela direção, vice - direção, três coordenadores pedagógicos e uma orientadora pedagógica. Possui duas professoras responsáveis pelo atendimento educacional especializado para atender aos alunos portadores de necessidades educacionais especiais.

Revisitando o Regimento Escolar (2014), percebe-se pela filosofia da escola a preocupação com a formação integral do aluno e com o seu protagonismo na sociedade:

A Escola busca a formação integral do ser humano, capaz de construir o conhecimento e de agir de forma consciente na sociedade, alicerçado pelos princípios democráticos, éticos, críticos e solidários. A instituição acredita que através da interação família-escola-comunidade, o aluno possa transformar a realidade social na qual está inserido, sendo protagonista da sua própria história. (RE, p.5)

O objetivo geral da escola (RE, 2014, p.5), é levar o aluno a construção do conhecimento, valorizando-se como pessoa consciente da sua atuação na sociedade, baseando-se sempre nos princípios democráticos, éticos, críticos e solidários.

\subsection{A Unidade Executora}

O conselho é o órgão colegiado responsável pela gestão da escola, em conjunto com a direção, representado pelos segmentos da comunidade escolar, pais, alunos, professores e funcionários. (RE, p.8)

A Unidade Executora denominada Conselho Escolar da Escola Municipal de Ensino Fundamental Presidente João Goulart, foi fundada no ano de 2002, com o objetivo habilitar a escola a participar do Programa Dinheiro Direto na Escola (PPDE) ${ }^{2}$. Atualmente a diretoria do conselho escolar é composta:

Tabela 1 - Composição do Conselho Escolar

\begin{tabular}{l|c}
\hline Segmento representado & Número de representantes \\
\hline Equipe gestora & 02 \\
\hline Professores & 03 \\
\hline Funcionários & 01 \\
\hline
\end{tabular}

\footnotetext{
${ }^{2}$ O Programa Dinheiro Direto na Escola (PDDE), conforme o Portal do FNDE, foi criado em 1995 com a finalidade de prestar assistência financeira, contribuindo para a manutenção da infraestrutura física e pedagógica, para as escolas públicas da educação básica e às escolas privadas de educação especial sem fins lucrativos. Disponível em: http://www.fnde.gov.br/programas/pdde . Acesso em: 30/10/2018.
} 


\begin{tabular}{l|c}
\hline Pais ou responsáveis & 06 \\
\hline Alunos & - \\
\hline Outros & 01 \\
\hline
\end{tabular}

Fonte: Estatuto do Conselho Escolar - Outubro/ 2017

Observando a tabela $n^{\circ} 01$ podemos observar a falta de representatividade do segmento alunos, que embora conste no estatuto, não acontece de fato.

Analisando as atas do Conselho Escolar, desde a fundação em 2002 até o ano de 2018, aconteceram uma média de três reuniões por ano e em geral o principal objetivo das reuniões é relacionado a aplicação de recursos financeiros recebidos do Programa Dinheiro Direto na Escola (PDDE). As assembleias gerais, conforme o livro de atas, foram registradas nas atas de número 01/2002, 02/2004, 01/2005, 01/2006, 01/2009, 01/2012, 03/2014 e 02/2017 realizadas somente para eleger as diretorias ou aprovar o estatuto.

\subsection{Referencial teórico}

Pensar em gestão democrática é pensar em democratização do acesso, do conhecimento e da gestão. O artigo 205 da Constituição Federal de 1988 afirma que a educação é um direito do cidadão e um dever do Estado e da família, direito que implica não somente ao acesso, mas na permanência e principalmente na aprendizagem com sucesso.

Utiliza-se o termo gestão da escola por ser mais abrangente e envolver o todo, aspectos pedagógicos e administrativos, pois o termo administração é considerado por Lück (2008, p.23) um enfoque muito limitado.

O provérbio tão antigo "manda quem pode, obedece quem tem juízo", contempla claramente as relações de poder, presente em todas as formas de dogmatismo e no autoritarismo ao longo da história. O gestor tem a palavra final? O poder é centralizado? Como se dá a participação e os processos decisórios?

O paradigma dominante ainda é tão presente no cotidiano das escolas, porém segundo Bordignon (2013), não existe um "dono da escola", ela pertence a comunidade e, para que haja comprometimento, suas ações devem ser pensadas no coletivo:

A quem pertence a escola pública? Se não houver a consciência de que a mesma pertence ao público, que constitui a escola e seu entorno, não haverá como envolver os atores, desencadear a efetiva participação. Se escola e seus objetivos pertencerem ao (à) diretor (a), ao governo, não há porque os professores, os funcionários, os agentes da comunidade, se sentirem comprometidos com ela (BORDIGNON, 2013). 
A Constituição Federal (1988), a Lei de Diretrizes e Bases da Educação Nacional (LDB/1996) e o Plano Nacional de Educação (PNE/2014-2024) contemplam a gestão democrática, prevendo a participação de todos os envolvidos no processo ensinoaprendizagem, alunos, professores, pais e comunidade local. Cada escola deve elaborar, coletivamente, a proposta pedagógica de acordo com a realidade e os anseios dos diversos segmentos representados em conselhos.

Segundo Paro (2016), um dos temas mais debatidos quando está em pauta a figura do diretor é o processo de escolha para provimento do cargo. Ele afirma que a grosso modo pode-se falar em três modalidades de escolha: nomeação pura e simples pelo poder executivo, concurso público, e eleição pela comunidade escolar.

A nomeação por critério político, em que o secretário de educação ou o chefe do poder executivo escolhe o ocupante do cargo, tendo como base o critério políticopartidário, é comumente considerada a pior alternativa, em virtude do clientelismo político que ela alimenta e a falta de base técnica que a sustente, já que o candidato é escolhido não por sua maior experiência e conhecimento de gestão e de educação, mas por sua maior afinidade com o partido ou o grupo no governo do estado ou do município (PARO, 2016, p.49; grifo nosso).

A eleição de diretores pela comunidade escolar e a participação dos segmentos em conselhos escolares é prevista na Meta 19 do Plano Nacional de Educação (PNE/2014-2024):

Meta 19: Assegurar condições, no prazo de dois anos, para a efetivação da gestão democrática da educação, associada a critérios técnicos de mérito e desempenho e à consulta pública à comunidade escolar, no âmbito das escolas públicas, prevendo recursos e apoio técnico da União para tanto.

Estratégias:

19.4. Estimular, em todas as redes de educação básica, a constituição e o fortalecimento de grêmios estudantis e associações de pais, assegurando-se lhes, inclusive, espaços adequados e condições de funcionamento nas escolas e fomentando a sua articulação orgânica com os conselhos escolares, por meio das respectivas representações;

19.5. Estimular a constituição e o fortalecimento de conselhos escolares e conselhos municipais de educação, como instrumentos de participação e fiscalização na gestão escolar e educacional, inclusive por meio de programas de formação de conselheiros, assegurando-se condições de funcionamento autônomo;

19.6. Estimular a participação e a consulta de profissionais da educação, alunos (as) e seus familiares na formulação dos projetos político-pedagógicos, currículos escolares, planos de gestão escolar e regimentos escolares, assegurando a participação dos pais na avaliação de docentes e gestores escolares (PNE, 20142024, p.83-84; grifo nosso).

Em relação à Meta 19, que trata da efetivação da gestão democrática, o Relatório do Segundo Ciclo de Monitoramento da Metas do Plano Nacional de Educação (PNE) - 2018, publicado pelo Instituto Nacional de Pesquisas Educacionais Anísio Teixeira (Inep), apresenta 
como indicador o percentual dos municípios que selecionam diretores das escolas públicas, da rede municipal de ensino, por meio de eleições e critérios técnicos de mérito e desempenho da educação básica nos municípios. Conforme a Figura 1:

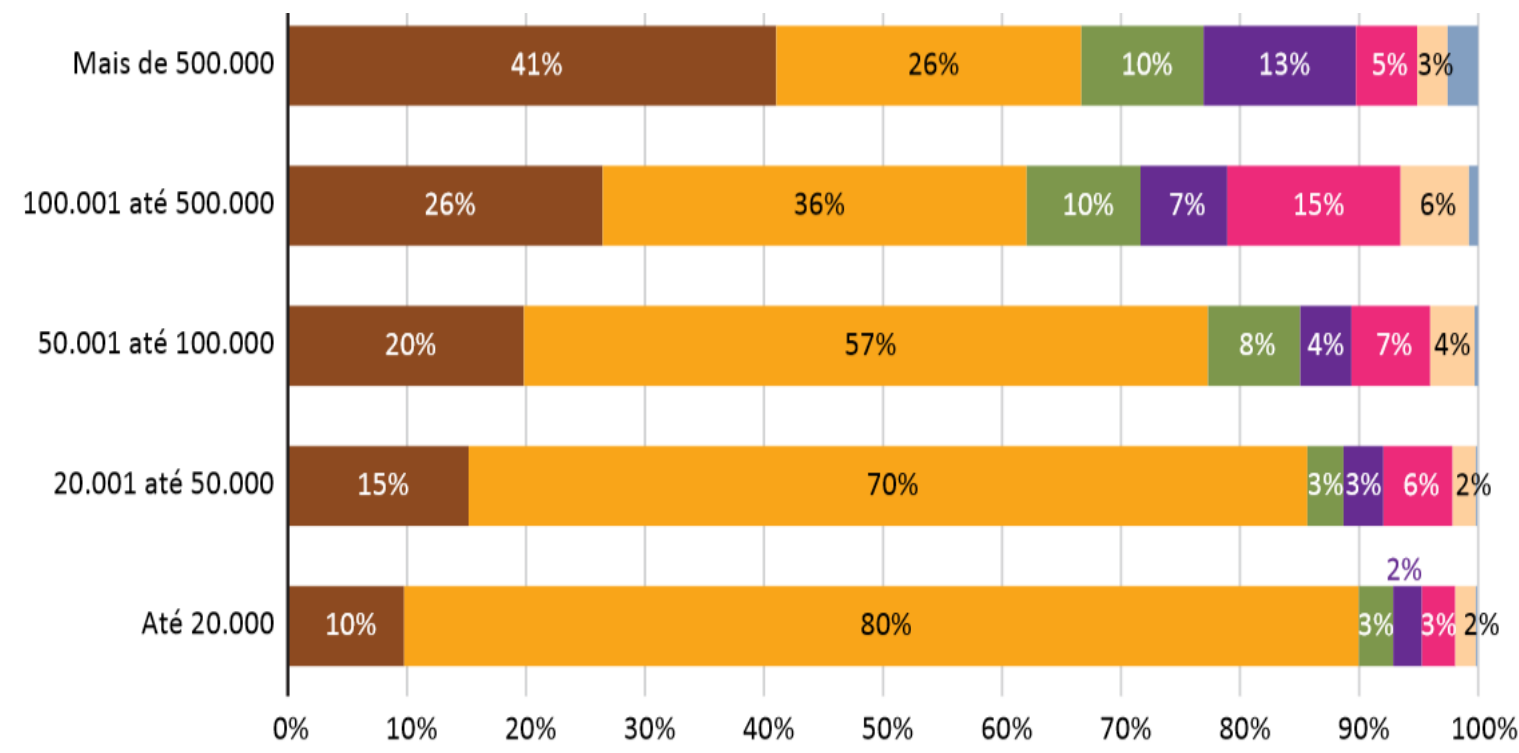

-Exclusivamente eleição Exclusivamente indicação —Exclusivamente concurso —Exclusivamente outras

- Eleição e outras formas Indicação e outras formas —Concurso e outras formas

Figura 1 - Formas de seleção dos diretores de escolas públicas municipais, por porte dos municípios - Brasil - 2014. Fonte: Dired/Inep com base em dados da Munic/IBGE (2014).

Entre os municípios de pequeno porte (Figura 1), está o município de Arroio Grande RS, que apresenta a forma exclusivamente por indicação para a ocupação dos cargos de direção nas escolas municipais. Conforme o artigo 57 do Plano de Carreira do Magistério Público de Arroio Grande - RS (PCMPAG, 2011, p.25), para ser indicado à direção, o único critério é que o professor seja pertencente ao quadro efetivo dos servidores municipais, não é exigido formação em gestão e nem a apresentação de um plano de gestão.

No ano de 2004, por meio da Portaria Ministerial No 2.896, de 17 de setembro de 2004, foi instituído o Programa Nacional de Fortalecimento dos Conselhos Escolares (PNFCE/2004), que tem por objetivo geral fomentar a implantação dos conselhos escolares, por meio da elaboração de material didático específico e formação continuada para os conselheiros escolares, através dos cadernos de formação. O programa destaca que o conselho escolar se constitui uma ferramenta importantíssima de exercício da cidadania.

Os segmentos devem estar representados para que a gestão tenha sucesso e o diretor não seja o dono da palavra, acontecendo então uma mudança de paradigmas como afirma Bordignon (2013): 
Essa nova forma de administrar a educação constitui-se num fazer coletivo, em processo permanente. Processo que é mudança contínua e continuada. Mudança que está baseada nos paradigmas emergentes da nova sociedade do conhecimento, que, por sua vez, fundamentam a concepção de qualidade na educação e definem, também, a finalidade da escola. (BORDIGNON, 2013)

\section{RESULTADOS E DISCUSSÃO}

Observa-se a necessidade de realizar estudos que considerem o fortalecimento da gestão democrática, por meio da revitalização do conselho escolar, com a formação da consciência da importância de participar das decisões coletivas. Os cadernos do Programa Nacional de Fortalecimento dos Conselhos escolares, são ricos em conteúdos e poderiam ser utilizados na escola para encontros de formações.

\section{CONSIDERAÇÕES FINAIS:}

A gestão democrática, garantida por lei, ainda está longe de se tornar uma realidade em nossas escolas, observa-se, ainda, falta de articulação e formação dos envolvidos no processo. O poder continua centralizado nas mãos do diretor.

Com os avanços das tecnologias e com o mundo globalizado é exigido da equipe gestora e dos docentes habilidades e competências que são adquiridas ao longo da carreira, na interação teoria e prática, e não apenas na graduação.

Segundo Marcelo Garcia (2009), o desenvolvimento profissional é um processo ininterrupto, uma atitude permanente de indagação, de proposição de perguntas e problemas e também de busca de soluções. Os profissionais da educação precisam, eles próprios, perceber e compreender a necessidade de formação. É um processo individual e coletivo que deve acontecer no ambiente de trabalho do professor.

A Escola Municipal de Ensino Fundamental Presidente João Goulart, prevê, em seu calendário anual, formações mensais no local de trabalho, dentro da carga horária do professor e também formações ofertadas pela Secretaria Municipal de Educação de Arroio Grande.

O caminho para as transformações tão necessárias na educação é o desenvolvimento profissional do educador ao longo da carreira.

As relações devem acontecer no diálogo e no respeito, através de uma mudança de paradigmas, sem dominador ou quem se curve para obedecer. O diretor não tem a palavra final e precisa contar com a colaboração de todos os envolvidos. 
A participação representativa de cada segmento faz com que aconteça a descentralização do poder do diretor. Como afirma Paro (2016), a gestão não tem a função de controlar, mas de mediar para alcançar os objetivos e acompanhar todo o processo, num trabalho coletivo.

\section{REFERÊNCIAS BIBLIOGRÁFICAS}

ARROIO GRANDE. Lei Municipal N. ${ }^{\circ}$ 2.614/2011. Plano de Carreira do Magistério Público Municipal.

BORDIGNON, Genuíno. Gestão da Educação: o município e a escola. Disponível em <https://genuinobordignon.wordpress.com/2013/06/11/gestao-da-educacao-o-municipio-e-aescola>. Acesso em 30 jul.2018;

BRASIL. Instituto Nacional de Estudos e Pesquisas Educacionais Anísio Teixeira. Relatório do $2^{\circ}$ Ciclo de Monitoramento das Metas do Plano Nacional de Educação - 2018. - Brasília, DF: Inep, 2018;

Gráfico, 1988;

Constituição da República Federativa do Brasil. Brasília: Senado Federal, Centro

. Lei $\mathrm{n}^{\circ} 13.005$, de 25 de junho de 2014. Aprova o Plano Nacional de Educação PNE e dá outras providências. Diário Oficial [da] República Federativa do Brasil, Brasília, DF, 25 de junho de 2014;

. Lei $\mathrm{n}^{\circ}$ 9.394/96, de 20 de dezembro de 1996. Estabelece as diretrizes e bases da educação nacional. Brasília, DF: Congresso Nacional, 1996;

Cadernos do Programa Nacional de Fortalecimento dos Conselhos Escolares. Brasília, 2004;

CHISTÉ, Priscila de Souza. Pesquisa-ação em mestrados profissionais: análise de pesquisas de um programa de pós-graduação em ensino de ciências e matemática. Ciênc. Educ., Bauru, v. 22 , n. 3 , p. $789-808,2016$;

COSTA, J. V. da; GUINDANI, M. K. Didática e Pedagogia do Diário de Campo na Formação do Assistente Social. Revista Virtual Emancipação, Ponta Grossa, 12(2): 265-278, 2012. <www.revistas2.uepg.br/index.php/emancipacao/article/view/3404/3294>. Acesso em 06 de out.2018;

E.M.E.F. PRESIDENTE JOÃO GOULART. Projeto Político Pedagógico. Arroio Grande, 2014;

Regimento Escolar. Arroio Grande, 2014;

Estatuto Social do Conselho Escolar. Arroio Grande, 2017; 
FREIRE P.; SHOR, I. Medo e Ousadia: o cotidiano do professor. 5. ed. Rio de Janeiro: Paz e Terra, 1986;

GADOTTI, Moacir. Pedagogia da Práxis. 4. ed. São Paulo: Cortez: Instituto Paulo Freire, 2004;

GARCÍA, C. M. Desenvolvimento Profissional Docente. Revista de Ciência da Educação, nº. Jan/Abril, 2009;

LÜCK, Heloísa. Concepções e processos democráticos de gestão educacional. Petrópolis, RJ: Vozes, 2006. Série: Cadernos de Gestão II;

Gestão IV;

Liderança em gestão escolar. Petrópolis, RJ: Vozes, 2008. Série: Cadernos de

LÜDKE, Menga, Marli E.D.A. André. Pesquisa em educação: abordagens qualitativas - São Paulo: EPU, 1986;

PARO, Vítor Henrique. Crítica da estrutura da escola. 2. Ed. São Paulo: Cortez, 2016.

RIBEIRO, Renato Janine. Não há inimigo pior do conhecimento do que a terra firme. Tempo Social; Rev. Sociol. USP, S. Paulo, 11(1): 189-195, maio de 1999;

THIOLLENT, Michel. Metodologia da pesquisa-ação. São Paulo: Cortez, 2011. 